\title{
Some Steps for Language Maintenance in The Society and Individual
}

\author{
Ramlan \\ Jabal Ghafur University (UNIGHA) Sigli, Aceh \\ Email:ramj.kajhu@yahoo.com
}

\begin{abstract}
Language is an arrangement of arbitrary symbols possessing an agreed-upon significance within a community. These symbols can be used and understood independent of immediate contexts, and are connected in regular ways. Naturally individual has the typical language characteristics which is influenced by the feeling, idea, emotion, situation and condition, articulation and cognition. Reading and speaking often and widely the textbook, watching/listening to television, films, radio and podcasts, networking and making friends with people, and starting a local language club are the tips for maintaining the individual's language. The accent, dialect, and status of language are comprehended as the reflection of individual language and consequently are closely realted to the society. The use of tribal language in the traditional ceremony, party, religious services, daily activities, local billboards are the tips for maintaining language in the society. A good language status is greatly affected by the individual's language competence and performance. Therefore, individual in a certain society is in charge to maintain the language.
\end{abstract}

Keywords: language, society, individual; maintenance

\section{INTRODUCTION}

Morris (1946) describes that "Language as an arrangement of arbitrary symbols possessing an agreed-upon significance within a community; furthermore, these symbols can be used and understood independent of immediate contexts, and they are connected in regular ways." Three main domains such as language, society and individual are argued through this theory. The language is built up by the mutual agreement of a community, which contains a 
number of individual. Therefore, without individual there would not be a community, and consequently there would not be a language.

Individual, society, and language are three interrelated domains in human lives. Language maintenance is cumpolsory responsibility of the users of the language. However, this expectation is far from the reality, where language individual and society are changed. Therefore, maintaining the language is crucial to be taken into account. The objectives of this paper are to explain the basic concept of language society, to explore fundamenally the language of individual, and to offer some influential tips for maintaning language individual and society.

\section{REVIEW OF LITERATURE}

\subsection{Language Society}

Language and society are the two different words. Society is defined as people in general, living together in communities, whereas language is a means of communication to express our feelings, thoughts, ideas, etc. The language and the society are closely related and could not be separated. This is supported by Rampton (2004) who says:

"Linguistic ethnography generally holds that, to a considerable degree, language and the social world are mutually shaping, and that close analysis of situated language use can provide both fundamental and distinctive insights into the mechanisms and dynamics of social and cultural production in everyday activity."

The people who are in a certain society; of course have to have a different background of education, culture, economic, status or class, age, gender, etc.

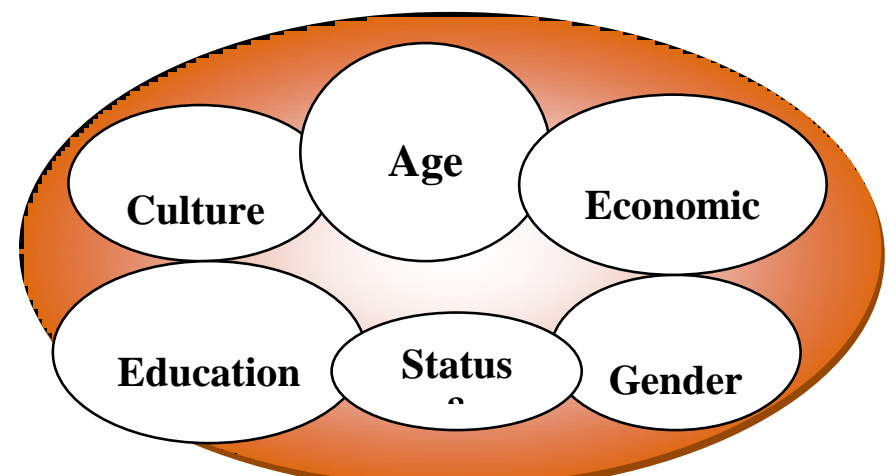

Figure 1: Different Background People in the Society 
The culture is concerned with 1) customs: an accepted way of behaving or of doing things in a society or a community; 2) beliefs: a strong feeling that something or somebody exists or is true; 3 ) art: the use of the imagination to express ideas or feelings, particularly in painting, drawing or sculpture, and 4) singing; way of life and social organization of a particular country or group. The economic consists in the development of wealth of a country, an area or a society. The status or class is the level of wealth of people in the society. The age is the number of years that a person has lived or a thing has existed. And the gender refers to the sex of human being: male and female. The existance of a language is greatly influenced by those different backgrounds above.

\section{a) Social Variation}

The distinctive backgrounds of the people mentioned above are closely related to the use of language in the society. As a consequence, social variation is emerged. The social variation, accordin to Holmes (2001), is concerned with the language variety used by a particular society.

Therefore, the relationship between society and language is emerged with a number of variations. The multi-dimensional society is resulted in the variation in language such as the accent, dialects, and social status or class (Edwards: 2009). The relationship is displayed on figure 2.

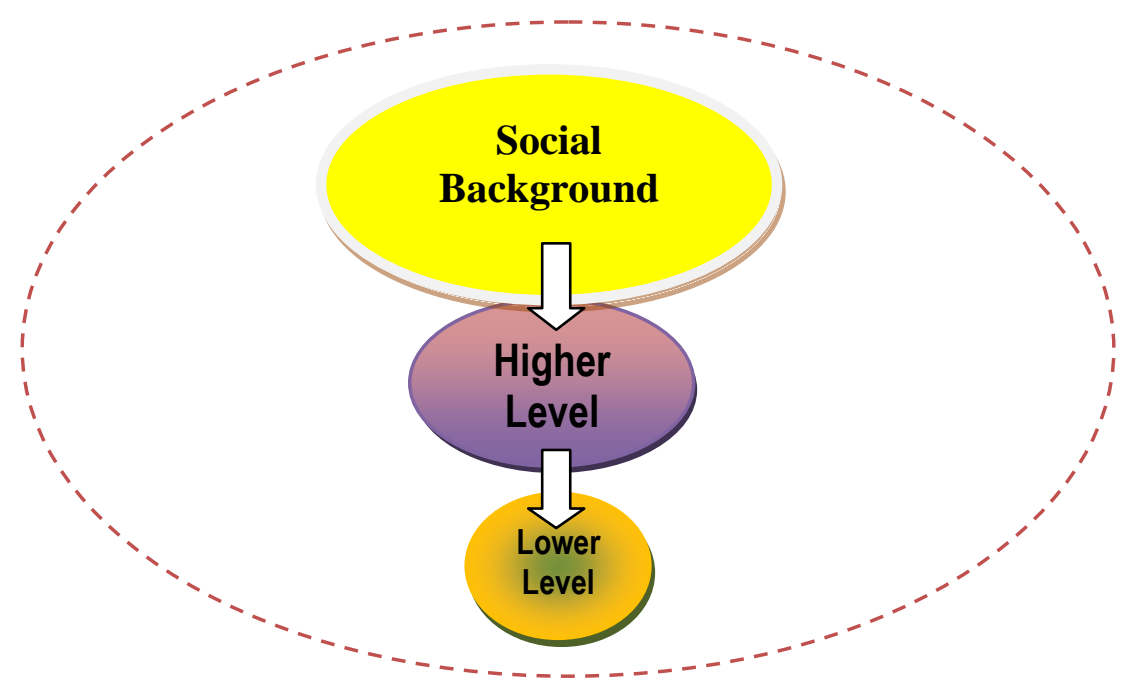

Figure 2: Social Background, Higher and Lower Level of Society 
The different background (e.g. accent, dialects, and social status or class) of people in the society is influential to the use of standard language by the higher level of the people and non-standard language by lower level of the people. The more man has a good culture, economic, status or class, age, education, and gender; the more standard the language will be used, and vice versa.

\section{b) Social Accent}

Social accent is the way of pronouncing the words of a language that shows which country, area or social class a person comes from (Cooper: 1989). On the other words, an accent is a certain form of a language spoken by a subgroup of speakers of that language which is defined by phonological features. In line with this definition, accent therefore is identical to pronouncing the words. In English the standard pronunciation is termed as RP which stands for 'Received Pronunciation' (Montgomery: 1996).

One of the examples is in the early twentieth century, in England, a person who spoke with a regional accent was most unlikely to belong to the upper class. In contrast, upper class people learn to speak RP (Holmes: 2001). The accent of the best educated and most prestigious members of English society belongs to RP. It is usually was 'received' at royal court, and it is sometimes identified with 'the Queen's English'. The different accent of English is well-shown by Holmes (2001):

Diana: Have you heard-Jonathan engaged to that northern girl-from Cumbria!

Reg: She may be northern but I assure you she is very acceptable. Her father is a lord, and a rich one at that! She has had the best education money to buy. Those traces of northern accent are fashionable these days my dear!

\section{DISCUSSION}

Dialects are simply language varieties which are distinguishable by their vocabulary, grammar and pronunciation; the speech of people from different social, as well as regional, groups may differ in these ways (Homes:2001). Therefore, there are at least three different domains of a dialect: 
(1) Vocabulary: It refers to all the meaningful words that a person knows and uses.

(2) Grammar: The rules in a language for changing the form of words and joining them into sentences.

(3) Pronunciation: the way in which a language or a particular word or sound is pronounced.

These three elements are differently used by the different society, and consequently the way people speak is characterized by patterned variation. The patterns are fascinating and reflect the social factors which are significant in a society (Holmes: 2001).

\section{A. Social Status}

\section{i. Castes}

Castes deals with the system of dividing society into classes based on differences in family origin, rank, and wealth. People can be grouped together on the basis of similar social and economic factors. The evidence can be seen from India where social divisions are very clear-cut. In this country, the caste systems are determined by birth, and strict social rules governed the kind of behavior appropriate to each group (Holmes: 2001).

Some quite clear differences in Indian languages, for example, between the speech of Brahmins and non-Brahmins castes. The Brahmin word for 'milk' in the kanaka language, for instance is 'haalu', while non-Brahmin dialects say 'aalu'. The Tamil Brahmin word for 'sleep' is 'tuungu', while non-Brahmin dialects use the word 'orangu' (Holmes: 2001).

\section{ii. Social Class}

Social class is defined as one of the groups of people in a society that are thought of as being at the same social and economic level. The social variation, which is divided into: social accent, social dialect, and social status, has the close relationship with the use of language by the people in the society (Holmes: 2001). The distinguishable use of language reflects on vocabulary, pronunciation-vowel and consonant, and grammar.

The term social class is used as a shorthand term for differences for between people which are associated with differences in social prestige, wealth, and education. There is a consistent relationship between social class and language patterns. People from different classes speak differently. Many pairs of word were identified which is claimed distinguished the speech of upper-class English people ('U speaker') from the rest ('non- U speaker'). U speaker used sitting room rather than lounge (non-U), and referred to the lavatory rather than the (non-U) toilet 
Consonant is a speech sound made by completely or partly stopping the flow of air being breathed out through the mouth. The following is some examples of pronouncing consonant differently by the people with different social status and economic (Holmes: 2001).

\section{The sound " $h$ "}

In West Yorkshire and Norwich, the highest social group drops sound " $h$ " and the lowest group omits it (e.g. hotel, honey, habit, harmer, etc.)

\section{The sound " $r$ "}

In New York, the more high social class people are the more " $r$ " is pronounced (e.g. car, chair, teacher, computer, register, etc.

Vowel is viewed as a speech sound in which the mouth is open and the tongue is not touching the top of the mouth, the teeth, etc., for example [a:], [e], and [ə:]. In New Zealand, the higher social class people are, the closer their pronunciations to RP. This is seen when they pronounce the sound diphthong "au" and "ou" for words: bought, how, open, go, our, etc (Holmes: 2001)

Grammar is the rules in a language for changing the form of words and joining them into sentences. The grammar pattern is also affected by the different social group. On average it was found that people from lower class families use more vernacular forms (language used for ordinary people ) than people from middle class families (Holmes: 2001). For instance:

"I finished that book yesterday"

"I finish that book yesterday"

\section{B. Tips for Maintaning the Language Society}

Holmes (2001) suggests some influential domains of a language:

1) If families from a minority group live near each other and see each other frequently, this also helps them maintain their language;

2) For those who immigrate, the degree and frequency of contact with the homeland is a factor which may contribute to language maintenance;

3) Marriage to a majority group member is the quickest of ensuring shift to the majority group language for the children;

4) Obviously a group who manage to ensure their language is used in settings such as school or their place of worship will increase the chance pf language maintenance; 
5) Education, law and administration, religion and the media are crucial domains in language maintenance.

Based on the theory above, therefore, it can be said that the activities in maintaining language are as follows:

1) Use the local language in the traditional ceremony and party, for instance, wedding party. Traditional ceremony is the ceremony which is being part of the beliefs, customs or way of life of a particular group of people that have not changed for a long time.

2) Use the local language in religious activities. This means that we have to use the local language for all the activities connected with religion or with a particular religion.

3) Use the local language for daily activities at home with the member of the family.

4) Use the local written language for a certain typical local billboards.

\section{Language Individual}

Any individual has the personality. Personal identity - or personality - is essentially the summary statement of all our individual traits, characteristics and dispositions; it defines the uniqueness of each human being (Edwards: 2009). The physical differences of human being could be in the forms of health: the condition of a person's body; weight: how heavy somebody/something is, which can be measured in, for example, kilograms or pounds; and height: he measurement of how tall a person or thing is, etc. Psychological is dealt with a person's mind. In terms of psychological aspect, the human being could be different in terms of feelings, thoughts, emotions, etc. These psychological features are linked to the code choise, which involves at least three parts: pronunciation, vocabulary, and grammar. The relationship is redisplayed below:

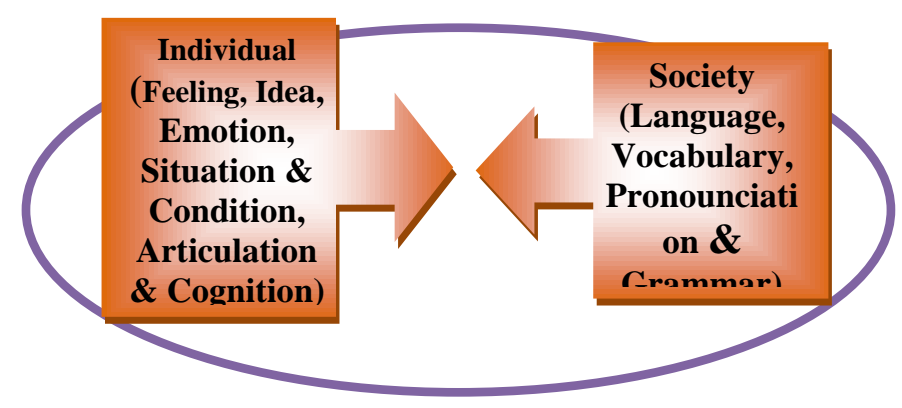

Figure 3: Relationship between Language Society and Individual 
Feeling is something that you feel through the mind or through the senses (e.g. happy, sad, upset, interested, afraid, hot, cold, warm, etc). Idea consists in a plan, thought or suggestion, especially about what to do in a particular situation. Emotion deals with a strong feeling such as love, fear or anger; the part of a person's character that consists of feelings. Situation and Condition are all the circumstances and things that are happening at a particular time and in a particular place when we are delivering our message to a listener (e.g. in the wedding party, campaign, raining, cloudy, etc). Articulation is related to the organ of speech used by the speaker to utter anything with sound. An organ in the mouth used for making speech sounds, such as the tongue, lips, or teeth. Cognition is viewed as the process by which knowledge and understanding is developed in the mind.

\section{a. Tips for Maintaing the Language Individual}

Language is iflunced by both internal and exteral factors in human beings. It means that maintaning the individual's competence and performanace in language is crucial to take into account. The following is the steps to maintain language competence (http://www. marketingtranslationblog.com/2009/05/07/how-to-maintain-your-language-skills-parttwo/comment-page-1/):

1) Read and speak often and widely the local language textbook

Reading and speaking are activities in which the message is expressed and grasped. As a consequnece, it is the practical way to enlarge our ability on local language.

2) Watch/listen to television, films, radio and podcasts which related to the local language The influence of mechanical instruments nowadays plays a crucial role to all aspects of human lives. The television, car, motor cycle, radio, tape, computer, handphone, telephone, tractor are common examples of mechanical instrument we use everyday. The use of these instruments is the other ways to maintain our local language ability. It is also practical because we can easily know the new terms used by the society of our local language.

3) Network and make friends with people who speak your local languages

Networking deals with a system of trying to meet and talk to other people who may be useful to you in your work. And making friends is concerned with the increase of the number of our good relationship to another as friends or co-worker. Both networking and 
making friends are the reflections of the value of our sociability. Through these activities the speaker of local language can maintain his knowledge and skills of it.

4) Start a local language club

Another solution to maintain the local language is by starting a local language club. Local language club is a group of people who meet together regularly, for a particular activity such as practicing their speaking, listening, reading, and writing skills of the local language.

\section{CONCLUSION}

Language plays an important role in human lives. Language is of course used in the society, which is named language society. Language society is the language used in an extended social group that living together in communities. The people exist in a certain society; of course have to have a different background of culture, economic, status or class, age, gender, etc. in which are influential to the social accent, dialect, and status. However, using constantly the local language in the traditional ceremony and party in religious services, in daily activities, for a certain typical local billboards are tips in maintaining language in the society. The language of individual is the typical language used of a particular person. The typical characteristics of individual's language can be comprehended in the use of words, structure, pronunciation, etc. Reading and speaking often and widely the textbook, watching/listening to television, films, radio and podcasts, networking and making friends with people, and starting a local language club are the tips in maintaining the individual's language. A good status of language is affected by the individual's language competence and performance. Therefore, individual in a certain society is in charge to the language status and functions.

\section{REFERENCES}

Cooper, R.L. 1989. Language Planning and Social Change. Cambridge: Cambridge University Press.

Ewards, John. 2009. Language and Identity. New York: Cambridge University Press. 
Holmes, Janet. 2001. Learning About language: An Introduction to Sociolinguistics. England: Edinburgh Gate.

Jones. M.C. and Singh. I. 2005. Exploring language Change. London and New York: Routledge.

Montgomery, M. 1996. An Introduction to Language and Society: 2nd Edition, London: Routledge.

Morris, Charles. 1946. Signs, Language and Behavior. Englewood Cliffs, NJ: Prentice-Hall.

Rampton, Ben. 2004. Linguistic Ethnography: A Discussion Paper. Retrieved on 07 July 2010 from www.ling-ethnog.Org.uk.

Sapir, Edward. 1921. Language. NewYork: Harcourt Brace.

Schiffman, H.F. 1996. Linguistic Culture and Language Policy. New York and London: Routledge.

http://en.wikipedia.org/wiki/Language_planning. Accessed on March 4, 2014.

http://www.marketingtranslationblog.com/2009/05/07/how-to-maintain-your-language-skillspart-two/comment-page-1/. Accessed on March 5, 2014. 